\title{
Gastroplasty for Morbid Obesity
}

\section{Roentgen Evaluation and Spectrum of Complications}

\author{
Farooq P. Agha, ${ }^{1}$ Howard H. Harris, ${ }^{2}$ and Mohammed M. Boustany ${ }^{3}$ \\ 1 Department of Radiology, University of Michigan Hospital, Ann Arbor, Michigan, USA; and Departments of Surgery, \\ ${ }^{2}$ West Virginia University Hospital, Morgantown, West Virginia, and ${ }^{3}$ Charleston Area Medical Center, \\ Charleston, West Virginia, USA
}

\begin{abstract}
With the advent of autosuture devices, gastric partitioning procedures have recently become popular surgical treatment of morbid obesity. One such procedure is Gomez gastroplasty. Using an autosuture device a small gastric fundal pouch, having a reservoir capacity of $60 \mathrm{ml}$ and communicating with the remaining stomach through a $12 \mathrm{~mm}$ stoma is created along the greater curvature of the stomach. A 3-0 polyprolene internal seromuscular suture is used to reinforce the stoma without incising the stomach. This gastroplasty is extremely attractive because of the disarming simplicity of the procedure and its noninterruption of the normal sequence of the digestive tract.

This report is based on a joint review of 280 cases subjected to Gomez gastroplasty to combat morbid obesity. Postoperative radiological evaluation and the spectrum of observed complications are herein described.
\end{abstract}

Key words: Morbid obesity, surgical treatment of Gastroplasty, postoperative complications.

The prevalence of morbid obesity and modest successes of nonoperative management led to considerations of surgical solutions to the problem. Recently gastric partitioning procedures have become popular in the surgical treatment of morbid obesity. These procedures involve creating a partitioning of surgical staples that divide the stomach into a small proximal reservoir and a large distal segment. The small proximal gastric pouch having a capacity of $50-75 \mathrm{ml}$ is the common feature of all partitioning procedures. Continuity between the proximal reservoir and the

Address reprint requests to: Farooq P. Agha, M.D., Department of Radiology, University of Michigan Hospital, Ann Arbor, MI 48109, USA remaining gastrointestinal tract may be established by creating a small defect in the partition of staples or by performing a gastroenterostomy. The partitioning defect, measuring $10-12 \mathrm{~mm}$ in diameter, may be in the central portion of the staple line, along the greater or lesser curvature of the stomach. Anastomotic techniques have involved gastrogastrostomy or gastrojejunostomy (loop or Roux-en-Y). The surgical literature is replete with a variety of names for these procedures, including gastric bypass $[1,2]$, gastric stapling [3], gastric plication [4], gastric partitioning [5], stapled gastric partition [6], high gastric reduction [7], proximal gastric exclusion, and gastroplasty [2, $7,8]$.

Mason [4] was first to choose the term gastroplasty in 1971 for gastric partitioning procedure. He abandoned this procedure after a year because it failed to achieve the desired results. He made no attempt to calibrate the capacity of the proximal pouch and the size of the stoma. In 1977 Mason's gastroplasty was given a second look by Gomez [8] and Pace et al. [5]. The purpose of this report is to (a) familiarize radiologists with the technique, roentgen appearance, and evaluation of Gomez gastroplasty; and (b) report the spectrum of anatomic complications demonstrable radiographically.

\section{Historical Background}

The surgical management of morbid obesity is barely a quarter of a century old and has undergone many changes in the interval. The jejunoileal bypass procedures were attempts to limit caloric absorption by reducing the length of small intestine. In $1954 \mathrm{Kre}-$ men et al. [10] reported on an experimental $90 \%$ end-to-end jejunoileal bypass in dogs. In 1963 Payne et al. [11] reported a clinical study of 10 patients undergoing jejunocolic or jejunoileal bypass. In 1969 Payne and DeWind [12] introduced end-to-side jejunoileal bypass and reported their results with 2 series of patients $[13,14]$. Scott et al. [15] popularized the end-to-end jejunoileal bypass with the bypassed segment anastomosed to the transverse or sigmoid colon and reported results of their 2 large series [16, 17]. 


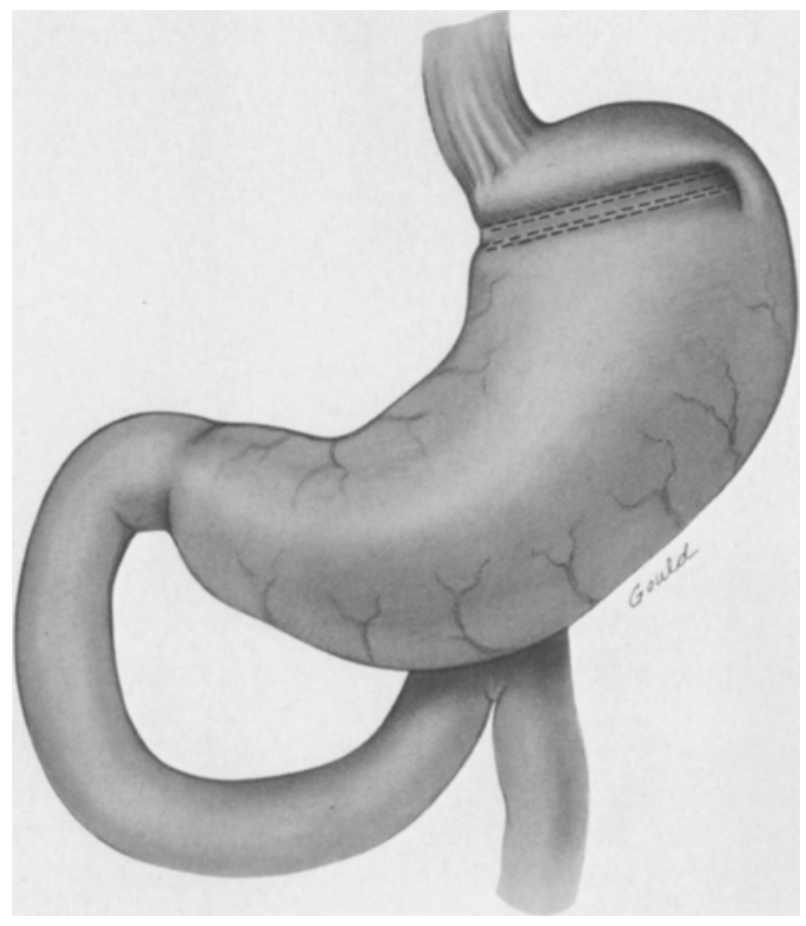

Fig. 1. Artist's conception of Gomez gastroplasty. A $60 \mathrm{ml}$ proximal fundic pouch communicates through a $12 \mathrm{~mm}$ stoma along the greater curvature to the distal stomach

In 1967 Mason and Ito [1] introduced gastric bypass operations, and in 1973 Printer \& Mason [2] reported their experience with 130 gastric bypasses and 56 gastroplasties. Mason, in 1971, was first to use the term gastroplasty to signify the partitioning of the stomach into small upper and larger lower portions connected by a small passage. No measurements of the volume of the upper pouch or calibration of the stoma were attempted. This gastroplasty failed to achieve the desired results and was abandoned by the end of 1971. However, in 1977 Gomez [8] and Pace et al. [5] reexamined Mason's gastroplasty. Gomez's modification of gastroplasty [18] consists of using an autosuture device and a specially prepared C clamp, thus creating a $60 \mathrm{ml}$ fundic pouch and a $12 \mathrm{~mm}$ channel located on the greater curvature of the stomach communicating with the distal stomach (Fig. 1). In the Gomez type I procedure the unsupported channel gradually expanded, confirming the previous observations of Printer and Mason [2]. In the Gomez type II modification of the gastroplasty a narrow strip of Dacron mesh was used externally around the channel. Significant stenosis of the stoma developed in this group of patients, leading to a Gomez III modification of the gastroplasty in which an internal seromuscular suture ring with 3-0 polyprolene was used to reinforce the stoma. Significant advantages were noted in the Gomez III gastroplasty especially in reference to weight loss and marked reduction in complications.

In the Pace modification of gastroplasty, 3 staples are removed from the staple cartridge for partitioning the stomach [5]. No support is used to reinforce the stoma. Because of the $18 \%$ failure rate of this procedure, however, Gomez III reduction gastroplasty has become the popular surgical treatment of morbid obesity.
Table 1. Complications detected radiographically among 280 cases

\begin{tabular}{|c|c|c|}
\hline & No. of cases & Percentage \\
\hline 1. Disruption of proximal pouch & 4 & 11.2 \\
\hline 2. Stomal dilatation & 6 & 16.8 \\
\hline 3. Stomal stenosis & 2 & 5.6 \\
\hline 4. Complete obstruction of stoma & 1 & 2.8 \\
\hline 5. Staple line dehiscence & 6 & 16.8 \\
\hline 6. Gastric perforation & 1 & 2.8 \\
\hline 7. Intra-abdominal abscess & 2 & 5.6 \\
\hline Total & 22 & $8.1 \%$ \\
\hline
\end{tabular}

\section{Materials and Methods}

This series consisted of 280 patients who underwent Gomez III modification of gastroplasty [18] for treatment of morbid obesity at West Virginia University Hospital and Charleston Area Medical Center between July 1, 1979, and June 30, 1981. The study was designed to evaluate the roentgen appearance and spectrum of anatomic complications detectable radiographically. The mean age of patients was 30 years with a range of 18 to 54 years. Females predominated 192 to 88 . The mean number of kilograms overweight was $50 \mathrm{~kg}$ with a range of 45 to $90 \mathrm{~kg}$. The basic guidelines for selection of patients consisted of excessive weight of at least $45 \mathrm{~kg}$, obesity for at least 5 years, absence of severe metabolic or endocrine problems, and failure of nonsurgical methods to combat obesity. The preoperative workup consisted of oral cholecystogram, upper and lower gastrointestinal series, intravenous pyelogram, renal and endocrine workup, complete blood chemistries, and psychological evaluation of the patients. Postoperatively suspected perforations were evaluated by an upper gastrointestinal study using water-soluble contrast. Follow-up upper GI series were done with barium whenever an unsatisfactory clinical course was noted, if the patient stopped losing weight or actually began to gain weight. At the time of gastroplasty $18 \%$ of the patients had cholecystectomy for cholelithiasis. A liver biopsy was taken in all patients prior to closure.

Although the technical aspects of the gastroplasty are simple, the postoperative management is extremely difficult and important. All patients were given miniheparin 5,000 units every 8 hours prior to surgery and continued until discharge from the hospital. Early ambulation, meticulous tracheobronchial toilet, and withholding food for 4 days postoperatively were carried out. Average hospital stay was 6.5 days. First follow-up visit was arranged at 2 weeks, and subsequent monthly visits were scheduled for the next 6 months.

Complications evaluated were disruption of the proximal pouch, stomal dilatation, stomal stenosis or complete obstruction, staple line dehiscence, gastric perforation, and intra-abdominal abscesses. The radiological procedures used to evaluate these patients consisted of plain abdominal radiographs, UGI examination with water-soluble contrast media or barium, ultrasonography, body computed tomography, and gallium scanning. Oral isotope studies were performed in a few patients to evaluate the emptying time of the fundic remnant and gastroesophageal reflux.

\section{Results}

There were $22(8.1 \%)$ anatomic complications detected radiographically. The breakdown of these com- 

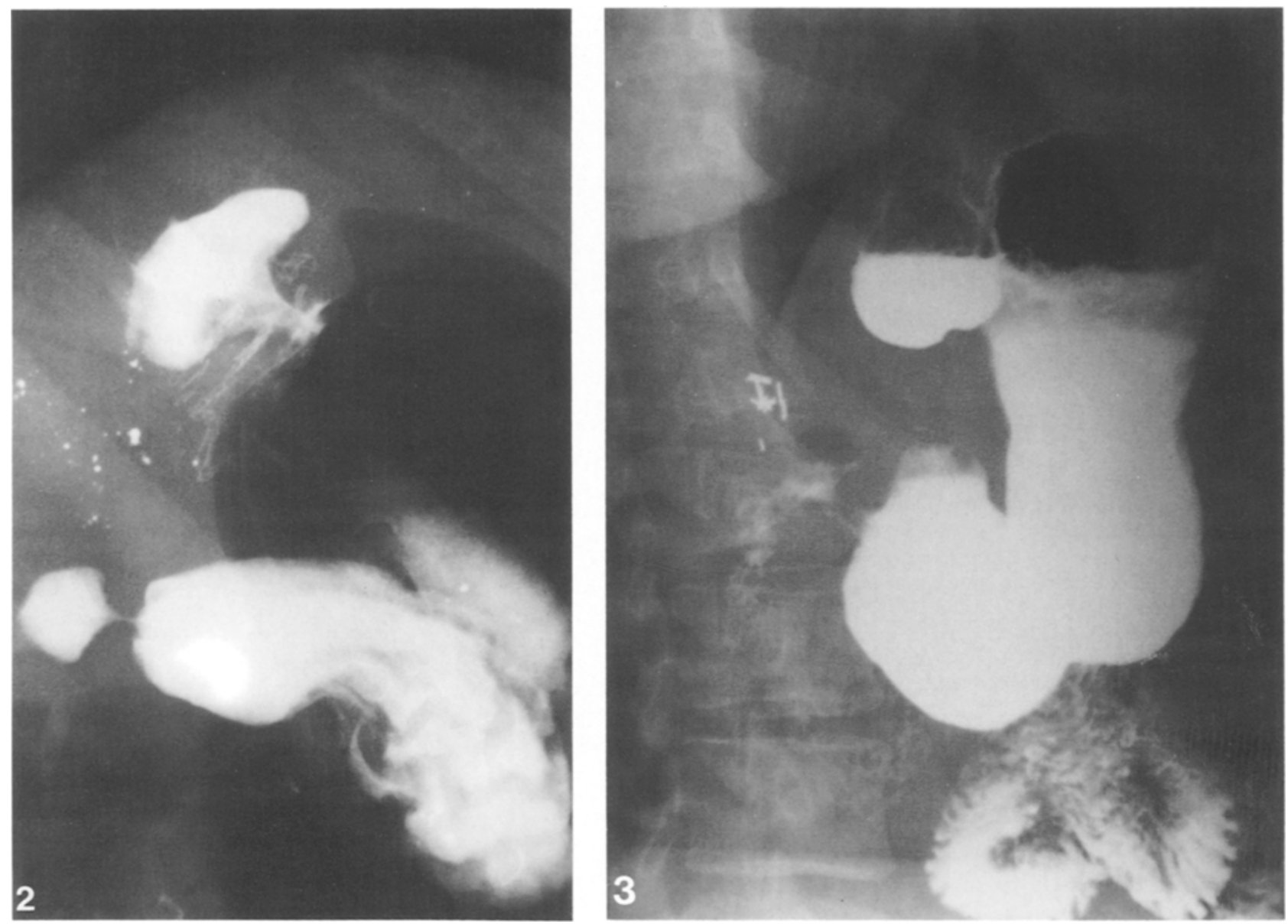

Fig. 2. Normal postoperative appearance of stomach following Gomez gastroplasty. The proximal fundic pouch has elliptical configuration and communicates through a $12 \mathrm{~mm}$ stoma to the distal gastric segment

Fig. 3. Globular configuration of the fundic pouch suggestive of stomal stenosis

plications is outlined in Table 1. Complications such as wound infection, dehiscence, and postoperative atelectasis or pneumonia were not included in this study.

\section{Discussion}

The disenchantment with jejunoileal bypass and gastric bypass procedures and their associated complications are well documented in the surgical and radiological literature [19-27]. Problems such as iron deficiency anemia, peripheral neuritis, dumping syndrome with symptomatic diarrhea, symptomatic bile reflux esophagitis and gastritis, enlargement of the anastomosis accompanied by weight gain, and questions raised regarding the fate of the bypassed seg- ment of the bowel led to rigorous search for a new operation $[5,8]$. The Gomez modification of gastroplasty has shown promising results and is well accepted by patients [18]. Prompt and accurate early diagnosis of complications is extremely important for proper management and to prevent early failure of gastroplasty.

Roentgen evaluation of the Gomez modification of gastroplasty entails evaluation of several components of the operation. These relate to the proximal gastric pouch, stoma, and staple line. In addition, a suspected gastric blowout or perforation should be evaluated by a UGI series using water-soluble contrast media. Plain abdominal radiographs, ultrasound, and body computed tomography and gallium scans were utilized to assess and localize a suspected abdominal abscess or abnormal fluid collections. 

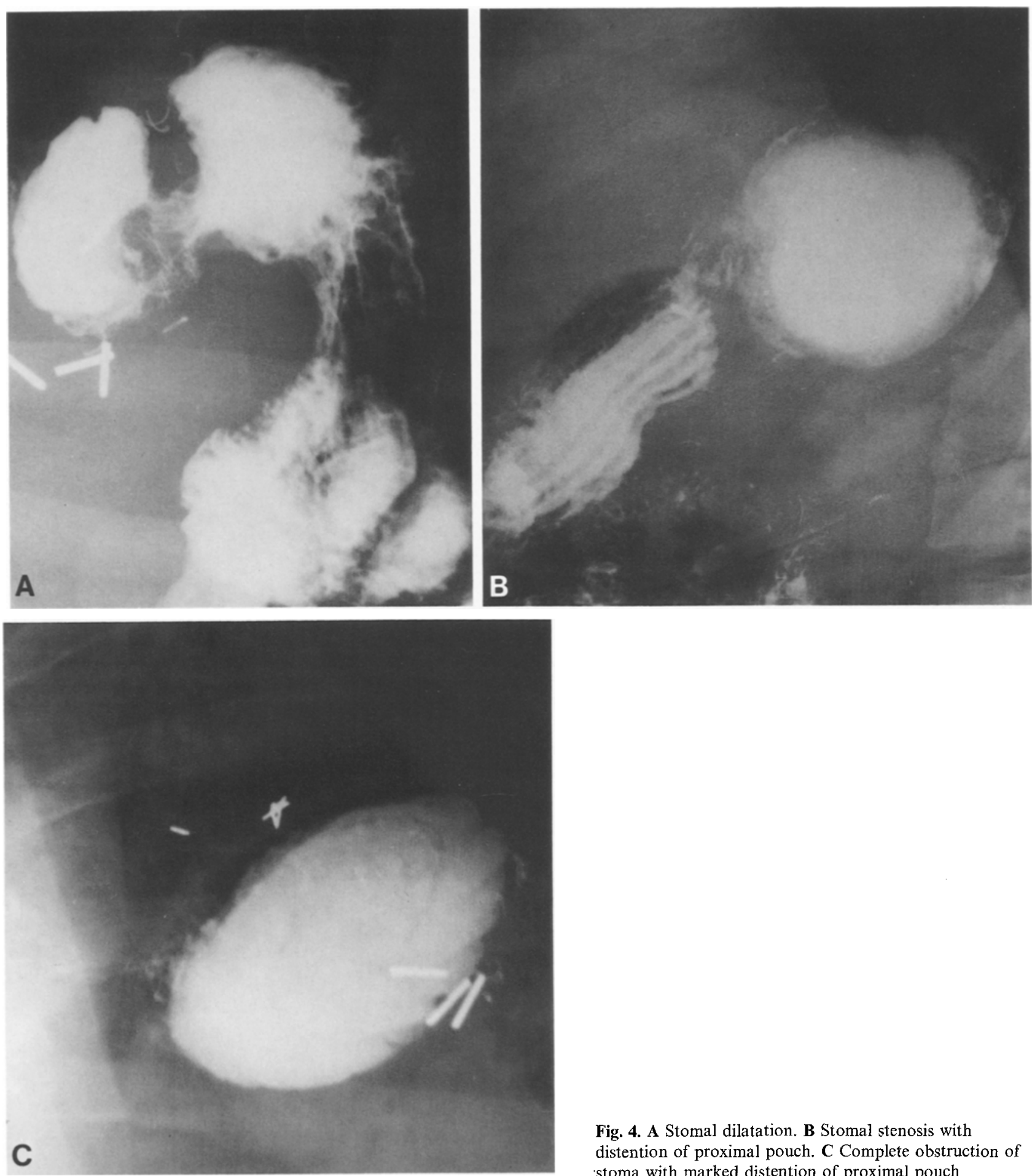

Fig. 4. A Stomal dilatation. B Stomal stenosis with distention of proximal pouch. C Complete obstruction of stoma with marked distention of proximal pouch

\section{Disruption of Proximal Pouch}

In Gomez gastroplasty the capacity of the proximal gastric pouch is $60 \mathrm{ml}$. This pouch is usually elliptical in shape (Fig. 2). Change in shape is an early sign of enlarging proximal pouch. As the pouch enlarges it may become globular in appearance (Fig. 3). Any change in the shape of the proximal gastric pouch should raise the suspicion for underlying abnormality such as stenosis of the stoma. Lewis et al. [25] have reported recently a physiologic study of the fundic remnant emptying rate using isotope-labeled solid and 

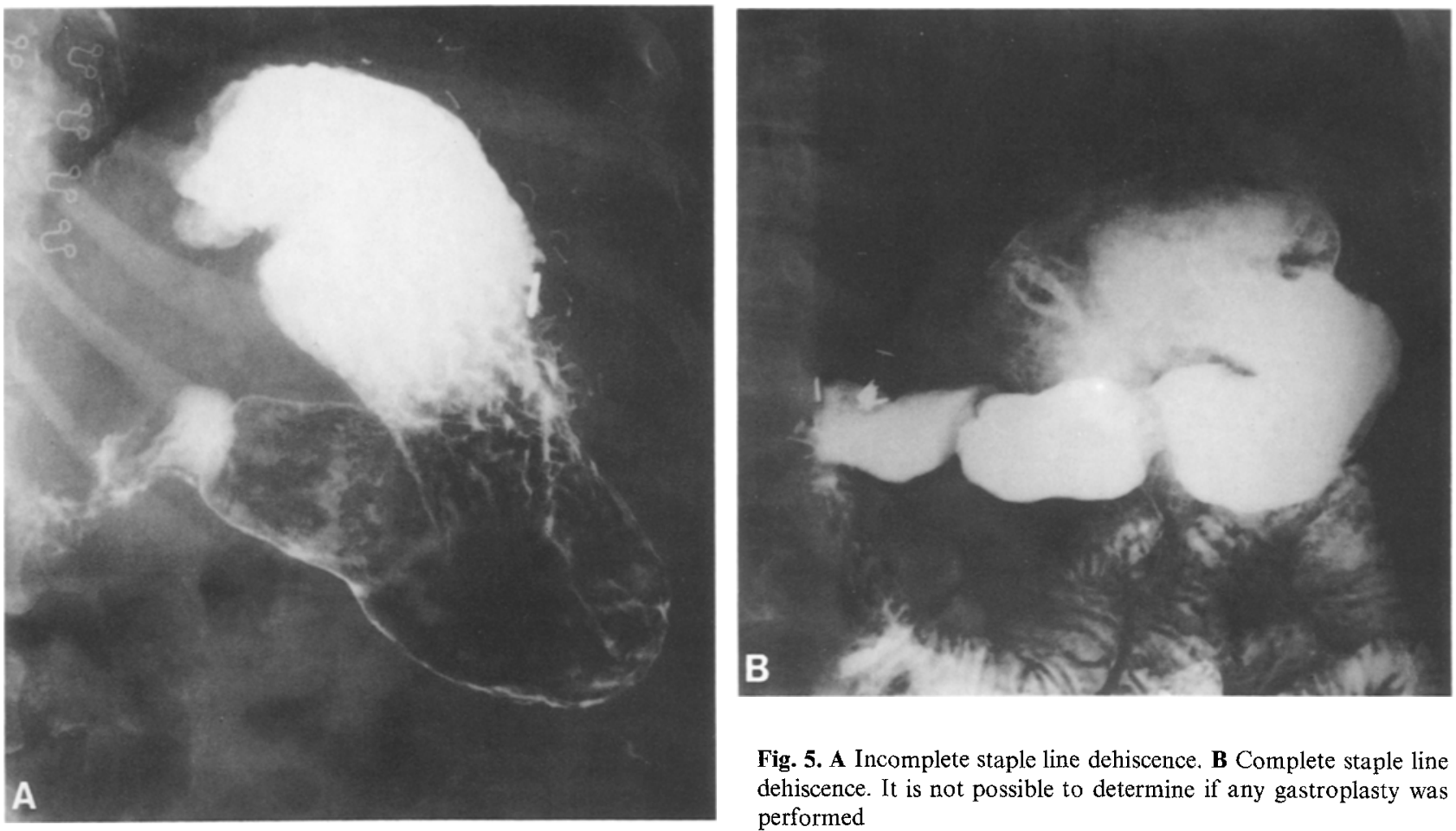

Fig. 5. A Incomplete staple line dehiscence. B Complete staple line dehiscence. It is not possible to determine if any gastroplasty was performed
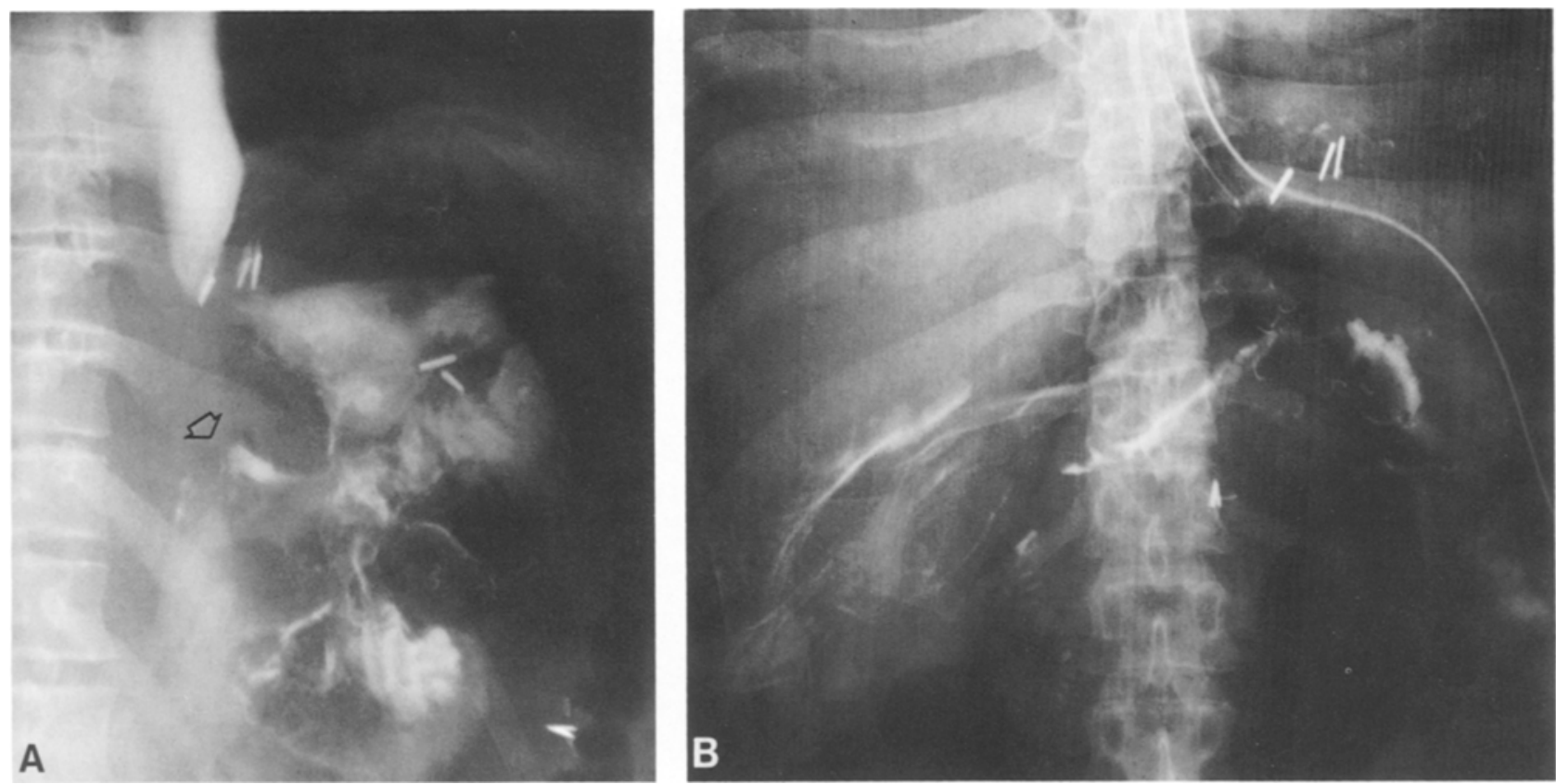

Fig. 6. Gastric perforation secondary to necrosis and disruption of staple line. A Upper GI series with Gastrograffin demonstrates leakage of the contrast material into the lesser sac (arrow). B Subsequent abdominal radiograph shows subhepatic collection of extraluminal contrast material

liquid materials. Acute perforation of the proximal gastric pouch may occur and Gomez [18] contends that this is due to ulceration in the fundic pouch. In this series 4 cases $(11.2 \%)$ of proximal pouch dis- ruption were noted (Table 1 and Fig. 6). Bezoar formation within the proximal gastric pouch may also occur, although it was not encountered in our series.

The initial postoperative UGI series serves to es- 
tablish the baseline appearance of the gastroplasty and is most useful for the recognition of subsequent findings. It is postulated that the proximal pouch will eventually enlarge in some patients. However, this change in size due to stretching is usually of limited extent. Villar et al. [26] studied the mechanism of satiety after gastric stapling and bypass. They showed that the feeling of fullness after both operations is secondary to distention of the fundic pouch (receptive relaxation) rather than due to increased intragastric pressure.

\section{Stomal Evaluation}

The conduit measuring $12 \mathrm{~mm}$ in diameter is the second major component of Gomez gastroplasty. A seromuscular internal ring suture using 3-0 polyprolene supports the stoma and prevents stretching or dilatation. Gomez's data confirm that once the channel is reduced to $12 \mathrm{~mm}$, the patients begin to lose weight. Gomez explained this by the equation $A=\pi R^{2}$. $A$ $12 \mathrm{~mm}$ channel has a $113 \mathrm{~mm}^{2}$ area opening. An increase of $2 \mathrm{~mm}$ produces an area opening of $153.8 \mathrm{~mm}^{2}$, or a $36 \%$ increase in surface area. Therefore even a modest increase in the stoma will require a revision. Stomal stenosis was noted in 2 patients (Fig. 4) who required revision. Stomal stenosis leading to complete obstruction of the stoma was also noted in 1 patient. Stomal dilatation occurred in 6 patients $(16.8 \%)$. Dilatation of the stoma remains one of the major complications of this procedure. With the use of $3-0$ and more recently $2-0$ polyprolene internal seromuscular suture, the stoma can be better reinforced [8].

\section{Staple Line Dehiscence}

Staple line dehiscence may be partial or complete. The increased incidence of staple line dehiscence led to justifying double staple line application. In Gomez gastroplasty 2 double rows of staples are used along with a specially designed $C$ clamp. The staple line dehiscence may occur acutely in the early postoperative period with necrosis of the staple line. Clinical observation and data obtained in animal experimentation indicate that the staple line is most susceptible to stresses of solid food bolus between the second and sixth postoperative weeks, predisposing to early failure of gastroplasty [6]. However, by the sixth to eighth postoperative week the staple line is as strong as uninjured stomach. Pace et al. [5] therefore restrict their patients to a liquid diet for 8 weeks postoperatively to minimize the incidence of staple line dehiscence.

Ellison et al. [6] demonstrated in animal studies that actual staple disruption from the posterior wall of the stoma leads to stomal dilatation and early failure of gastric partitioning. How this disruption actually takes place is not yet known. It is postulated that during the first 6-8 weeks before healing is complete the bolus of solid food leads to stretching of the channel followed by disruption of the staples through the posterior wall of the stomach.

In complete dehiscence of the staple line it is almost impossible to radiographically recognize that the stomach has even been operated on (Fig. 5). Although there is some concern that early stomal dilatation may be related to staple disruption, late stomal dilatation may not be related to the disruption of staples. In this series 6 cases of staple line dehiscence ( 3 complete and 3 incomplete) were noted. Revision was required in all of these patients.

\section{Gastric Perforation}

Acute gastric perforation usually occurs within the first $24-72$ hours after surgery. Plain radiographs of the abdomen and upper gastrointestinal examination using water-soluble contrast media should be utilized to detect this complication. Only 1 case of gastric perforation was noted (Fig. 6). Necrosis and disruption of the staple line led to gastric perforation in this patient. Emergency revision and splenectomy were performed.

The double row of 2 staple lines should be at least $2 \mathrm{~cm}$ apart to avoid gastric necrosis at the staple line. The potential space between 2 rows of double staple lines should be reduced to minimum. Delayed gastric perforation as reported in cases of gastric bypasses was not seen in our patients.

\section{Intra-abdominal Abscess}

Two patients developed subphrenic abscesses. The diagnosis was readily established by plain abdominal radiographs and ultrasonography and further confirmed by computerized body tomography and gallium scanning. In gastroplasty anastomotic leaks have not been a major problem since the stomach is not incised and anatomic continuity of the gastrointestinal tract is maintained.

\section{References}

1. Mason EE, Ito C: Gastric bypass in obesity. Surg Clin North Am 47:1347-1351, 1967

2. Printer KJ, Mason EE: Gastric bypass for the relief of morbid obesity. Arch Surg 106:428-433, 1973

3. Elliott $\mathrm{J}$ : More help for the morbidly obese - gastric stapling. JAMA 240:1941, 1978 
4. Tretbar LL, Taylor TT, Sifers EC: Weight reduction, gastric plication for morbid obesity. J Kans Med Soc 77:488-490, 1976

5. Pace WG, Martin EW, Tetirick T, Fabri PJ: Gastric partitioning for morbid obesity. Ann Surg 190:392-400, 1979

6. Ellison CC, Martin EW, Laschinger J, Mojzisik C: Prevention of early failure of stapled gastric partitions in the treatment of morbid obesity. Arch Surg 115:528-533, 1980

7. Long M, Collins JP: The technique and early results of high gastric reduction for obesity. Aust NZ J Surg 50:146-150, 1980

8. Gomez CA: Gastroplasty in morbid obesity. Surg Clin North Am 59:1113-1120, 1979

9. Mason EE: Gastroplasty. In Major Problems in Surgery. Philadelphia: W.B. Saunders Co., 1981, pp 386-417

10. Kremen AN, Linner JH, Nelson CH: Experimental evaluation of the nutritional importance of proximal and distal small intestine. Ann Surg 140:439-448, 1954

11. Payne JH, DeWind LT, Conners RR: Metabolic observations in patients with jejuno-ileal shunts. Am J Surg 106:273-289, 1963

12. Payne JH, DeWind LT: Surgical treatment of morbid obesity. Am J Surg 118:141-147, 1969

13. Payne JH: Surgical treatment of obesity - sixteen years experience. Arch Surg 106:432-437, 1973

14. DeWind LT, Payne JH: Intestinal bypass surgery for morbid obesity - long term results. JAMA 236:2298-2299, 1976

15. Scott HW Jr, Sandstead HH, Brill AB, Barko H, Younger RK: Experience with a new technique of intestinal bypass in the treatment of morbid obesity. Ann Surg 174:560-572, 1971

16. Scott HW Jr, Dean RH, Shull HJ, Abram HS, Weff W, Younger RK, Brill AB: New considerations in use of jejunoileal bypass in patients with morbid obesity. Ann Surg 177:723-735, 1973
17. Scott HW Jr, Dean RH, Shull HJ, Gluck F: Results of jejunoileal bypass in 200 patients with morbid obesity. Surg Gynecol Obstet 145:661-673, 1977

18. Gomez CA: Gastroplasty in the surgical treatment of morbid obesity. Am J Clin Nutr 33:406-415, 1980

19. Balthazar EJ, Goldfine S: Jejuno-ileal bypass roentgenographic observations. AJR 125:138-142, 1975

20. Jewel WR, Hermreck HS, Hardin CA: Complications of jejunoileal bypass for morbid obesity. Arch Surg 110:1039-1042, 1975

21. Hermreck AS, Jewel WR, Hardin CA: Gastric bypass for morbid obesity - results and complications. Surgery 80:498-505, 1976

22. Moss AA, Goldberg HI, Kochler RE: Radiographic evaluation of complications after jejuno-ileal bypass surgery. $A J R$ 127:737-741, 1976

23. Cohen WN, Mason EE, Blorner TJ: Gastric bypass for morbid obesity. Radiology 122:609-612, 1977

24. Moffat RE, Peltier GL, Jewell WR: The radiological spectrum of gastric bypass complications. Radiology 132:33-36, 1979

25. Lewis GP, James JO, Datz MD, Nelson JA: Radiographic evaluation of the gastric stapling procedure for obesity in 100 patients. Paper presented at the 29 th annual meeting of The Association of University Radiologists, April 22-24, 1981, New Orleans, LA

26. Villar HV, Burk TF, Wangestein SL: Mechanism of satiety after gastric stapling and gastric bypass. Surg Forum 30:353-355, 1979

27. Poulous A, Peat K, Loriman TG, Hatfield DR, Griffin WO: Gastric operation for the morbidly obese. AJR $136: 867-870$, 1981

Received: November 18, 1981; accepted: January 18, 1982 